\title{
Tinjauan Etika Periklanan dalam Konten Kreatif (Analisis Semiotik Iklan Shopee Versi Blackpink)
}

\author{
Ria Octavani, Sinta Paramita \\ Ria.915150038@stu.untar.ac.id,Sintap@fikom.untar.ac.id \\ Fakultas Ilmu Komunikasi Universitas Tarumanagara
}

\begin{abstract}
Along with the development of the era and also increasingly sophisticated technology, we can see advertisements in various types of media. Many companies from many category who advertise as creatively as possible to attract the attention of the audience so that audiences buy or use the product advertised. Shopee is one of the companies engaged in e-commerce also advertising the Shopee brand itself. Shopee also has its own creative ideas to make the audience increasingly shop online through Shopee. So that in November 2018, Shopee chose Blackpink as an actor in the Shopee ad. But in the end the ad must be lowered because it is considered to have violated the broadcasting code of ethics in Indonesia. But apart from the broadcasting code of ethics, there is also an advertising ethic that must be adhered to for every advertiser. In this study, researchers discussed the application of ethical principles of advertising to Blackpink's version of Shopee ads. The purpose of this study is to analyze and explore the ethics of advertising with Blackpink's version of Shopee ads. The method used by researchers is a qualitative method using content analysis and for the validity of the observed data, researchers are looking for some references that support this research.
\end{abstract}

Keywords: E-commerce, Shopee, Advertising Ethics, Advertising

\begin{abstract}
Abstrak
Seiring perkembangan zaman dan juga teknologi yang semakin canggih, iklan sudah dapat kita lihat di berbagai macam media. Banyak perusahaan dari berbagai bidang yang memasang iklan sekreatif mungkin untuk menarik perhatian khalayak agar khalayak membeli atau menggunakan produk yang diiklankan. Shopee salah satunya perusahaan yang bergerak dibidang e-commerce juga mengiklankan brand Shopee itu sendiri. Shopee pun juga memiliki ide kreatifnya tersendiri untuk membuat khalayak semakin sering berbelanja online melalui Shopee. Sehingga pada bulan November 2018, Shopee memilih Blackpink sebagai pemeran pada iklan Shopee. Namun pada akhirnya iklan tersebut harus diturunkan karena dianggap telah melanggar kode etik penyiaran di Indonesia. Tapi terlepas dari kode etik penyiaran, adapula tentang etika periklanan yang harus dipatuhi bagi setiap pengiklan. Dalam penelitian ini, peneliti membahas penerapan prinsip etika periklanan pada iklan Shopee versi Blackpink ini. Tujuan dari penelitian ini adalah untuk menganalisis dan mendalami etika periklanan terhadap iklan Shopee versi Blackpink. Metode yang digunakan oleh peneliti adalah metode kualitatif dengan menggunakan analisis isi dan untuk validitas data yang diamati, peneliti mencari beberapa referensi yang mendukung penelitian ini.
\end{abstract}

Kata Kunci: E-commerce, Shopee, Etika Periklanan, Iklan 


\section{Pendahuluan}

Tanpa disadari, sekarang iklan sudah mulai bisa kita lihat dimana saja. Bahkan jika dibandingkan dengan iklan zaman dulu, iklan zaman sekarang sudah semakin kreatif dan lebih menarik sehingga masyarakat akan tertarik untuk membeli produk yang diiklankan atau mengunjungi situs yang diiklankan tersebut.

Dengan melalui iklan, sebuah merek, produk, atau jasa akan dikenal oleh masyarakat luas dan hal itu secara tidak langsung membuat merek, produk, atau jasa tersebut memiliki penilaian yang besar. Namun iklan tidak selalu mempromosikan suatu barang/jasa, tetapi bisa juga untuk memberikan suatu informasi atau pesan kepada khalayak yang melihat iklan tersebut.

Iklan merupakan pengemasan informasi dalam proses komunikasi yang disebarkan untuk mempengaruhi dan menarik minat seseorang, sekelompok orang atau siapa saja yang ingin menjual. Kekuatan periklanan memang terletak pada kecanggihan, kepiwaian dalam merumuskan ataupun mengorganisasikan pesan-pesan menarik perhatian dan mampu membangun pemaknaan bersama antara pengirim pesan iklan dengan khalayak.

Dan pada saat ini, banyak sekali perusahaan yang kecil maupun yang besar berlomba-lomba untuk membuat dan memasangkan iklan berhubungan dengan perusahaan agar masyarakat tidak hanya mengenal barang/jasa yang diiklankan tetapi juga mengetahui perusahaan yang berkontribusi dengan barang/jasa tersebut. Bahkan beberapa perusahaan menampilkan public figure yang sedang trend agar masyarakat lebih tertarik lagi. E-commerce menjadi salah satu media yang sangat digemari pada zaman sekarang, karena kemudahannya untuk berbelanja hanya dengan mengandalkan media digital, tanpa perlu ada pertemuan antara penjual dengan pembeli. Salah satu perusahaan besar yang bergerak dibidang e-commerce yaitu Shopee juga membuat iklan dengan menampilkan girlband korea yang sedang naik daun saat ini yaitu Blackpink.

Dalam iklan tersebut, memperlihatkan Blackpink (brand ambassador Shopee) yang menari seperti dalam lagu terbaru mereka yaitu DDU-DU DDU-DU namun dengan latar belakang berwarna oranye (warna dasar dari Shopee) dan ada logo Shopee. Diakhir dari video iklan tersebut, menampilkan salah satu anggota Blackpink yaitu Lisa kemudian menampilkan semua anggota Blackpink. Jika dilihat, dalam iklan video tersebut hanya ingin membesarkan nama Shopee di berbagai bagian dunia dan juga menyampaikan bahwa semua yang dibutuhkan ada di Shopee.

Namun, setelah beberapa lama iklan Shopee tersebut tayang di TV dan juga media sosial seperti Youtube, iklan tersebut dikritik oleh beberapa masyarakat Indonesia dan akhirnya kritikan tersebut tersampaikan hingga ke Komisi Penyiaran Indonesia (KPI) dan memutuskan untuk memblokir iklan tersebut. Hal ini membuat sebagian besar masyarakat Indonesia heboh dan banyak yang berkomentar tidak setuju dengan keputusan ini dan menganggap bahwa keputusan ini sangat aneh bahkan tidak masuk akal. Bahkan tidak hanya masyarakat biasa yang berkomentar, tetapi banyak juga kalangan artis Indonesia yang ikut berkomentar dan tidak setuju juga dengan keputusan yang telah dibuat oleh KPI.

Dalam penelitian ini memperlihatkan "Bagaimana kode etik periklanan dalam meninjau konten kreatif dalam periklanan (analisis terhadap iklan Shopee versi Blackpink) ?" Berdasarkan rumusan malah yang dijabarkan, maka tujuan dari penelitian ini adalah untuk mendalami kode etik periklanan yang terdapat dalam konten kreatif dengan studi kasus iklan Shopee versi Blackpink. 
Penulis berharap penelitian ini dapat memberikan manfaat bagi pembaca dari segi praktis dan akademis. Penulis juga berharap penelitian ini dapat menjadi acuan dan refrensi bagi penelitian serupa di kemudian hari.

Penelitian ini menerapkan beberapa teori sebagai acuan dan mempermudah penelitian yaitu sebagai berikut:

\section{Teori Komunikasi}

Menurut Handoko dalam buku Ngalimun dengan judul Ilmu Komunikasi Sebuah Pengantar Praktis mendefinisikan komunikasi merupakan proses pemindahan pengertian dalam bentuk gagasan atau informasi dari seseorang ke orang lain, yang melibatkan lebih dari sekedar kata-kata yang digunakan dalam percakapan, tetai juga ekspresi wajah, intonasi, dan sebagainya. Dan perpindahan efektif memerlukan tidak hanya transmisi data, tetapi bahwa seseorang mengirim berita dan menerimanya sangat tergantung pada keterampilan tertentu (membaca, menulis, mendengar, berbicara, dan lain-lain) (Ngalimun, 2017).

\section{Teori Periklanan}

Periklanan (Advertising) adalah suatu proses komunikasi yang melibatkan sponsor tertentu, yaitu si pengiklan, yang membayar jasa sebuah media massa atas penyiaran iklannya, misalnya melalui program televisi. Adapun iklannya itu sendiri biasanya dibuat atas pesanan si pengiklan tersebut, oleh sebuah agen atau biro iklan; atau bisa saja melalui Humas (Public Relation) lembaga pemasang iklan tersebut (Suhendang, 2010).

Dengan berbagai tipe iklan yang berbeda dan memiliki peran yang berbeda juga, maka kita bisa mengidentifikasi tujuh tipe iklan berdasarkan pada situasi iklan, antara lain sebagai berikut :
a. Brand
b. Retail atau iklan lokal
c. Direct Response Advertising
d. Business to Business Advertising
e. Advertising Institusional
f. Advertising Nirlaba
g. Iklan Layanan Publik

\section{Teori Etika Periklanan}

Dalam membuat suatu iklan, tidak hanya menampilkan apa yang menarik, tetapi iklan itu juga harus sesuai dengan etika periklanan yang ada di dalam Etika Pariwara Indonesia (EPI). Terdapat banyak sekali tata krama yang ada di dalam Etika Pariwara Indonesia, dan semuanya harus diperhatikan jika ingin membuat suatu iklan.

\section{Metode Penelitian}

Pendekatan penelitian yang digunakan oleh penulis adalah pendekatan kualitatif dengan menggunakan analisis wacana. Objek dalam penelitian ini adalah konten kreatif dari iklan Shopee versi Blackpink ini. Dalam penelitian ini, metode pengumpulan data yang digunakan adalah dengan dokumentasi, observasi, dan juga analisis isi dari iklan Shopee versi Blackpink ini. 


\section{Hasil Temuan dan Diskusi}

Dalam penelitian ini, penulis mengamati setiap adegan yang ada pada iklan Shopee versi Blackpink dan mengkaitkan dengan tata krama Etika Periklanan. Iklan Shopee versi Blackpink ini muncul pertama kali pada bulan November 2018 sebagai penampilan untuk menuju ulang tahun Shopee pada bulan Desember 2018 dan juga sebagai brand ambassador dari Shopee itu sendiri.

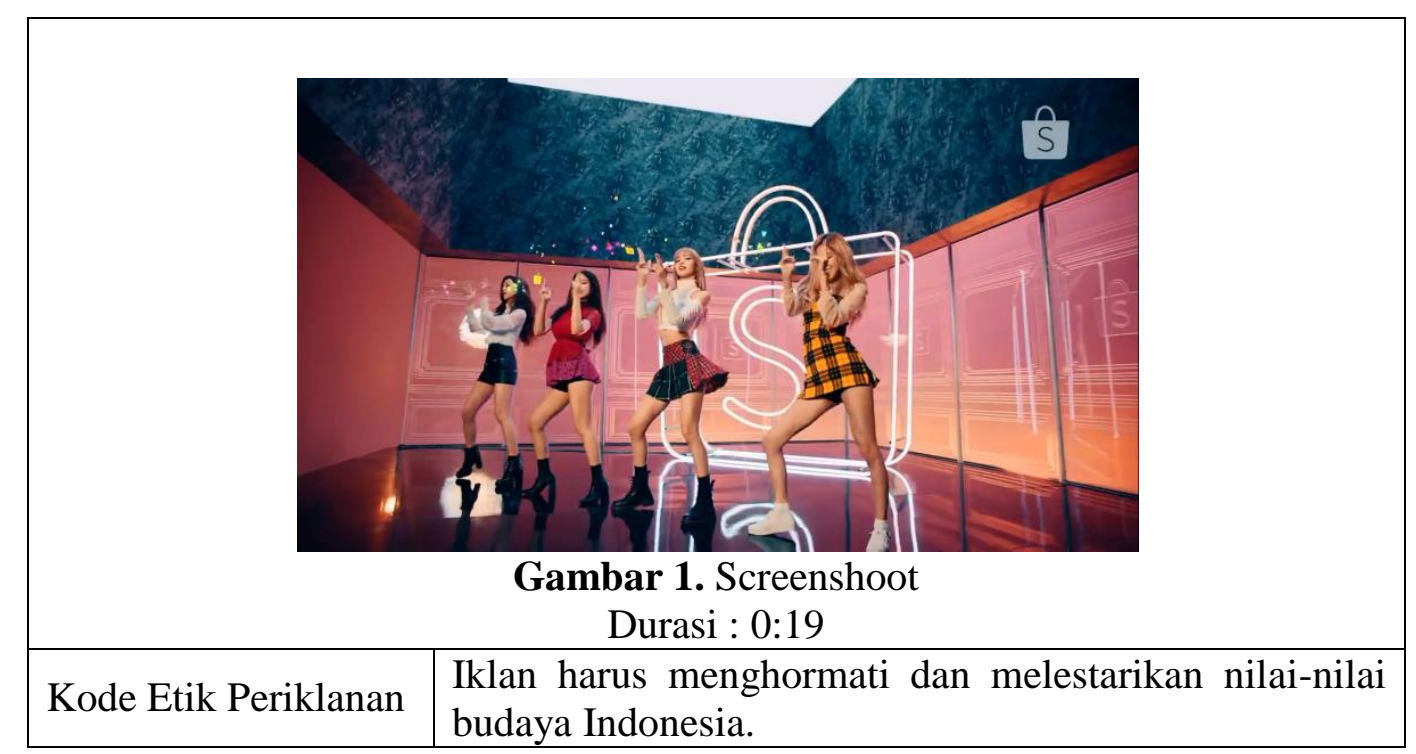

Dalam beriklan pun juga terdapat tata krama yang mengharuskan untuk menghormati dan melestarikan budaya-budaya Indonesia agar seluruh masyarakat yang melihat iklan tersebut sadar dengan budaya yang ada di Indonesia. Namun iklan Shopee ini tidak mencerminkan budaya yang ada di Indonesia, karena dalam iklan ini, Blackpink menggunakan pakaian yang cukup minim, tidak sesuai dengan kebudayaan Indonesia yang menjunjung tinggi norma kesopanan dalam menampilkan diri. Karena hal ini juga, iklan Shopee versi Blackpink ini sempat dikomentar oleh salah satu khalayak dan akhirnya diturunkan oleh Komisi Penyiaran Indonesia (KPI).

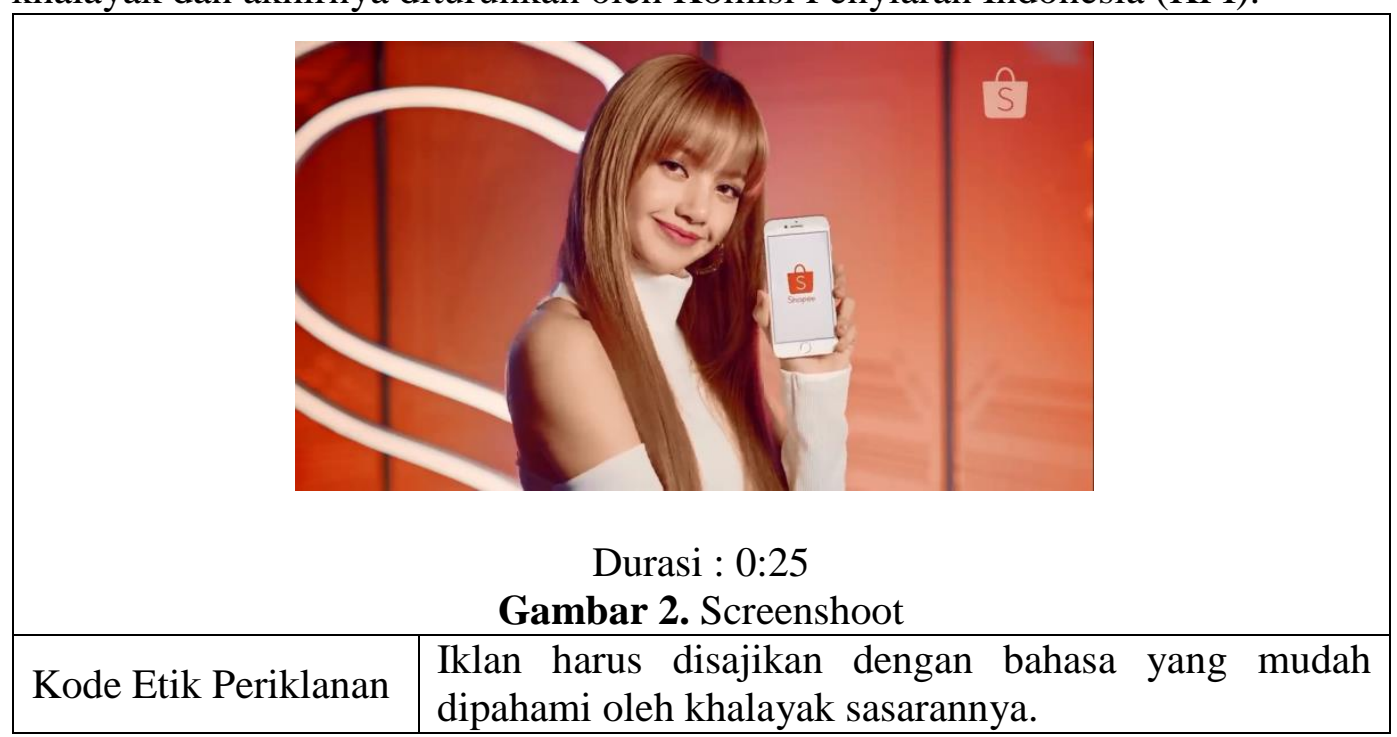

Dalam tata krama EPI, bahasa merupakan hal kedua yang dicantumkan dan dalam bahasa, terdapat banyak poin-poin yang harus dilakukan jika ingin membuat suatu iklan, salah satunya adalah iklan yang disajikan harus dengan bahasa yang 
mudah dipahami oleh khalayak agar khalayak paham dan mengerti isi iklan tersebut. Iklan Shopee versi Blackpink ini, ada satu kalimat yang diucapkan oleh salah satu anggota Blackpink yaitu Lisa, ia mengucapkan "beli semua di Shopee". Seperti yang diketahui, Lisa berasal dari negara Thailand dan merantau ke Korea Selatan sehingga menjadi artis K-Pop. Lisa diketahui mampu berbicara dalam 4 bahasa, Thailand, Korea, Inggris, dan Jepang. Dan Lisa sendiripun sudah pernah datang ke Indonesia sebelumnya dan hal ini juga membuat Lisa mudah dalam mengucapkan kalimat berbahasa Indonesia. Kalimat yang diucapkan di iklan Shopee tersebut sangat jelas dan dapat didengar oleh khalayak yang melihat iklan tersebut.

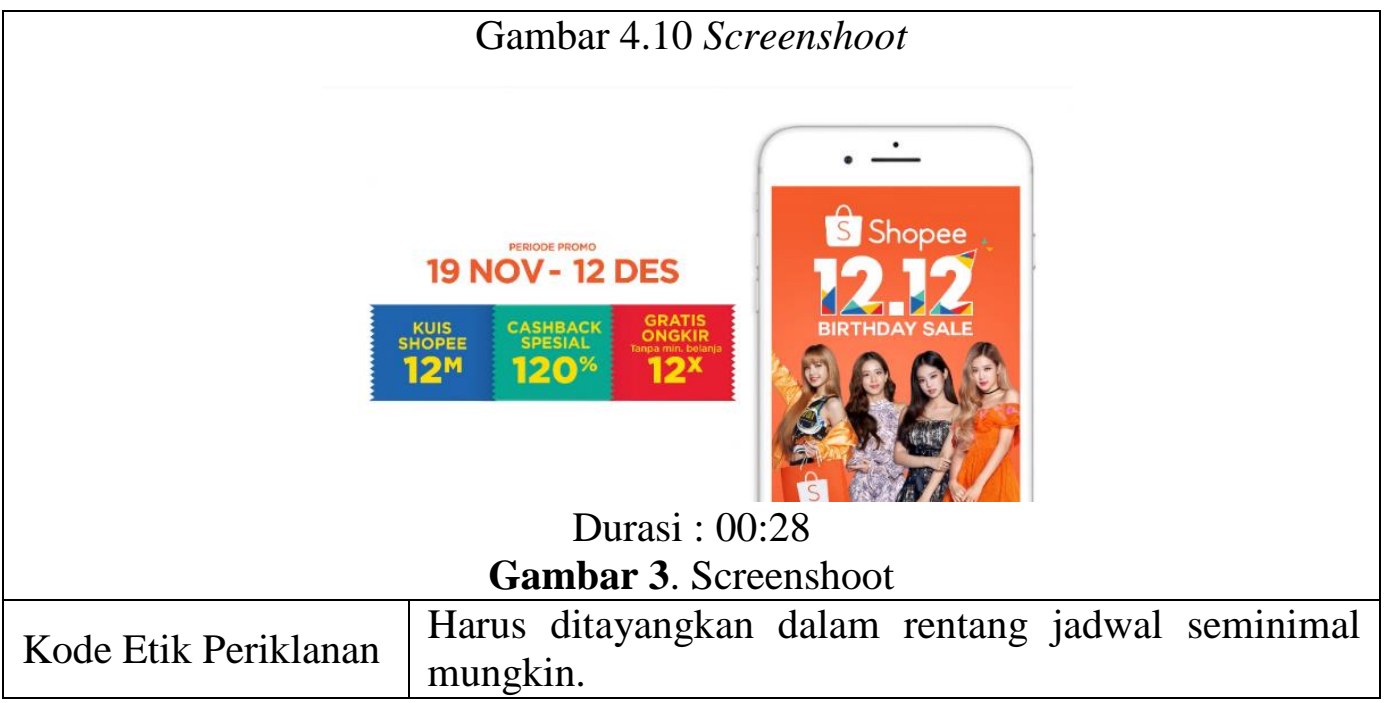

Menurut tata krama dalam beriklan berdasarkan EPI, jika iklan tersebut termasuk dalam iklan teaser, maka iklan tersebut harus ditayangkan dalam rentang waktu seminimal mungkin. Iklan Shopee versi Blackpink ini termasuk dalam iklan teaser, maka dari itu Shopee membatasi waktu penayangan iklan hanya dari pertengahan bulan November hingga pertengahan bulan Desember (19 November-12 Desember 2018) dan iklan ini hanya berdurasi 30 detik saja.

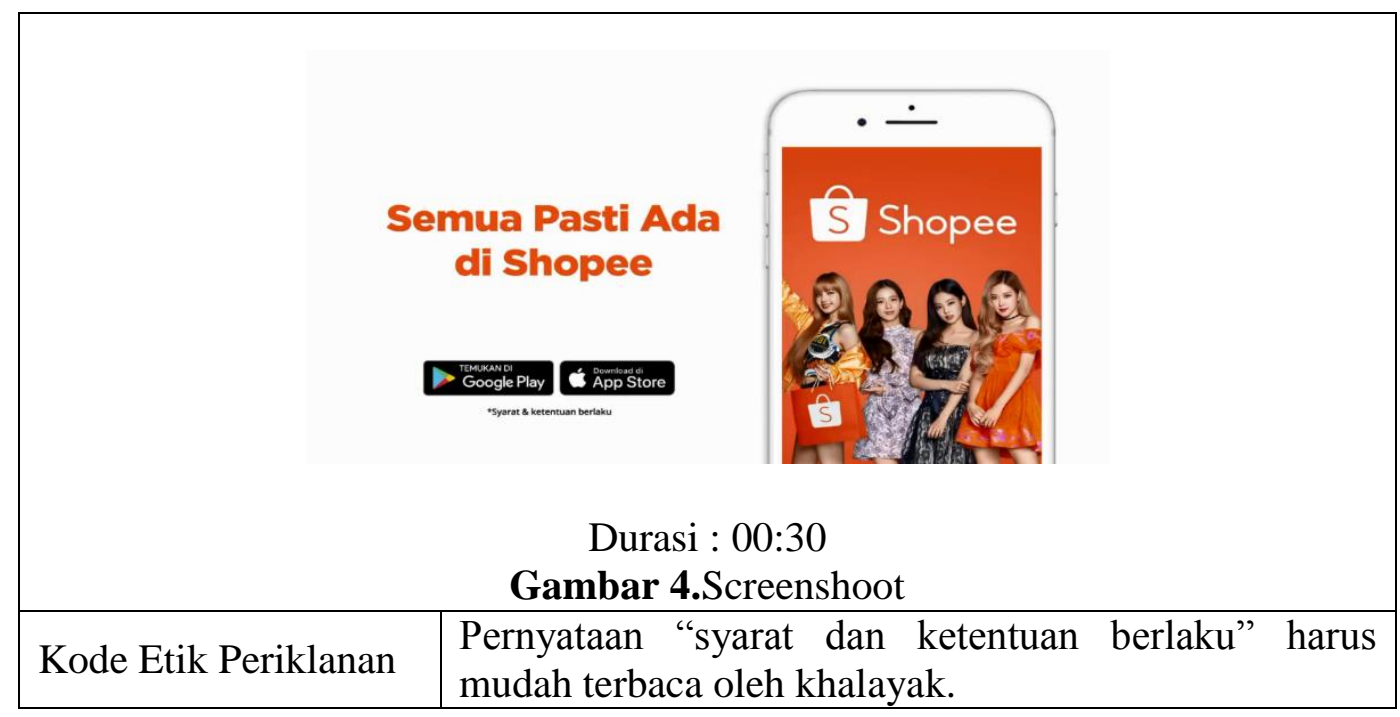

Pada akhir iklan dalam iklan Shopee versi Blackpink ini, terdapat sebuah kalimat yang menuliskan syarat dan ketentuan berlaku. Hal ini sesuai dengan tata 
krama dalam beriklan menurut EPI, hanya saja tulisan tersebut masih kurang terbaca jelas karena ukuran tukisan yang terlalu kecil dan terletak dibawah gambar Google Play dan App Store yang begitu dominan. Sehingga biasanya banyak khalayak yang salah memahami tentang beberapa hal yang sudah diterapkan dalam website maupun aplikasi Shopee itu sendiri.

Pada iklan Shopee versi Blackpink ini memiliki konsep periklanan yang sangat unik karena benar-benar disesuaikan dengan video klip DDU-DU DDU-DU yang sedang hits pada saat itu. Dan banyak juga masyarakat yang menyukai Blackpink, tidak hanya di Indonesia melainkan juga di seluruh dunia dan pada akhirnya CEO Shopee pun memilih Blackpink sebagai brand ambassador Shopee. Dengan ini, Shopee pun berinisiatif untuk membuat iklan bersama Blackpink ini menggunakan konsep yang sama dengan video klip lagu Blackpink terbaru pada saat itu yaitu DDUDU DDU-DU.

Jika dilihat pada durasi iklan tersebut dan jadwal penayangan yang cukup singkat, iklan Shopee ini termasuk sebagai iklan penggoda (teaser). Dan dalam Etika Pariwara Indonesia pun sudah menuliskan beberapa peraturan-peraturan yang harus ditaati dalam beriklan, tidak hanya dari isi iklan saja, melainkan dari pemeran iklan pun ada tata kramanya.

Dan menurut analisis, tata krama pertama yang dilanggar oleh iklan Shopee ini adalah bagian syarat dan ketentuan dan juga bagian budaya. Di dalam Etika Pariwara Indonesia menuliskan bahwa jika ada syarat dan ketentuan dalam iklan tersebut, haruslah bisa terlihat jelas dan terbaca oleh khalayak yang melihatnya, namun dalam iklan tersebut, terdapat tulisan syarat dan ketentuan tetapi tulisan yang terlalu kecil dan terletak dibawah gambar logo Google Play Store dan App Store yang begitu besar dan terlihat dominan. Jika khalayak kurang teliti, maka tulisan syarat dan ketentuan tersebut pasti tidak terlihat dan akan terlewatkan begitu saja. Dan bisa saja membuat khalayak menjadi salah paham pada saat ingin berbelanja melalui Shopee.

Tata krama kedua yang dilanggar adalah dari segi budaya. Dalam Etika Pariwawa Indonesia, iklan yang ditayangkan di Indonesia harus menghormati dan melestarikan budaya-budaya Indonesia. Tetapi dalam iklan Shopee versi Blackpink ini tidak adanya mencerminkan budaya yang ada di Indonesia yang salah satunya adalah budaya Indonesia sangat menjunjung tinggi norma kesopanan, baik itu sopan dalam tutur kata, perilaku, maupun cara berpakaian.

\section{Simpulan}

Berdasarkan hasil penelitian yang telah dilakukan oleh penulis, disimpulkan bahwa dalam iklan Shopee versi Blackpink ini masih terdapat bagian yang melanggar etika periklanan. Hal tersebut bisa dilihat dari segi budaya dan syarat ketentuan yang telah ditulis dalam Etika Pariwara Indonesia. Namun ada juga beberapa hal yang telah dilakukan sesuai dengan etika periklanan. Seperti halnya iklan Shopee yang merupakan iklan teaser harus memiliki durasi yang singkat, dan lain sebagainya.

\section{Ucapan Terima Kasih}

Penulis mengucapkan terima kasih kepada Fakultas Ilmu Komunikasi Universitas Tarumanagara yang telah memberikan pelajaran selama perkuliahan dan juga kepada tim redaksi Jurnal Komunikasi Universitas Tarumanagara yang telah menerima artikel ini untuk dipublikasikan. 
Ria Octavani, Sinta Paramita: Tinjauan Etika Periklanan dalam Konten Kreatif (Analisis Semiotik Iklan Shopee Versi Blackpink)

\section{Daftar Pustaka}

Cangara, Hafied. 2011. Komunikasi Politik Konsep, Teori, dan Strategi. Jakarta: Rajawali

Dewan Periklanan Indonesia. 2014. Etika Pariwara Indonesia. Jakarta: Dewan Periklanan Indonesia Edisi Kedua.

Kriyantono, Rachmat. 2012. Teknik Praktis Riset Komunikasi. Jakarta: Kencana Prenada Media Group.

Moleong, J Lexy, Prof. Dr. 2009. Metode Penelitian Kualitatif. Bandung: PT. Remaja Rosdakaya.

Ngalimun, 2017. Ilmu Komunikasi Sebuah Pengantar Praktis. Yogyakarta: Pustaka Baru Press

Suhendang, Kustadi. 2010. Periklanan Manajemen, Kiat dan Strategi. Bandung: Nuansa

Susanto, E. (2016). Dinamika Pesan Iklan. Jurnal Komunikasi, 6(2), 1-9. doi:http://dx.doi.org/10.24912/jk.v6i2.28

Putra, N., \& Widayatmoko, W. (2018). Pengaruh Terpaan Iklan Billboard Lazada Versi Terbalik dan Promosi Word of Mouth Terhadap Tingkat Kesadaran Merek Lazada. Jurnal Prologia, 2(2), 450-457. doi:http://dx.doi.org/10.24912/pr.v2i2.3729

Lani, M., \& Widayatmoko, W. (2017). Etika Iklan \& Peradaban Sosial (Komodifikasi Masalah Sosial Dalam TVC Meikarta Dengan Analisis Semiotika Model Charles Sanders Pierce Dalam TVC Meikarta). Jurnal Koneksi, 1(2), 484-489. doi:http://dx.doi.org/10.24912/kn.v1i2.2028 